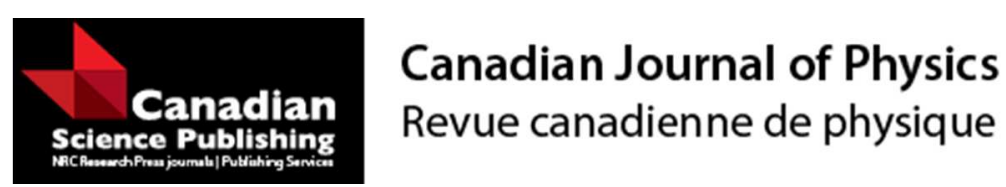

\title{
Magnetic quadrupole (M2) X-ray laser transitions from neon like arsenic As+23
}

\begin{tabular}{|r|l|}
\hline Journal: & Canadian Journal of Physics \\
\hline Manuscript ID & cjp-2016-0354.R2 \\
\hline Manuscript Type: & Comment \\
\hline Date Submitted by the Author: & 14-Aug-2016 \\
\hline Complete List of Authors: & $\begin{array}{l}\text { Mansour, Mohammad; Cairo University, } \\
\text { Abdelaziz, Wessameldin S.; Cairo Univ, laser metrology; Laser Institute } \\
\text { 9NILES), } \\
\text { El-Sherbini, Tharwat; Cairo University, Physics; Misr University for Science } \\
\text { and Technology, Basic Science }\end{array}$ \\
\hline Keyword: & $\begin{array}{l}\text { Neon-like arsenic, Relativistic calculations, X-ray laser, gain coefficients, } \\
\text { Magnetic quadrupole M2 }\end{array}$ \\
\hline & \\
\hline
\end{tabular}

\section{SCHOLARONE"}

Manuscripts 


\title{
Magnetic quadrupole (M2) X-ray laser transitions from neon like arsenic $A s^{+23}$
}

\author{
Mohammad Z. Mansour \\ National Institute of Laser Enhanced Sciences, \\ Cairo University, Egypt \\ E-mail: m_mansour@niles.edu.eg \\ Wessameldin S. Abdelaziz \\ National Institute of Laser Enhanced Sciences, \\ Cairo University, Egypt \\ E-mail: wessamlaser@yahoo.com \\ Tharwat M. El Sherbini \\ Laboratory of Lasers and New Materials, \\ Faculty of Science, Cairo University, Egypt \\ E-mail: thelsherbini@hotmail.com
}

November 8, 2016

\begin{abstract}
Neon-like arsenic $A s^{+23}$ are studied theoretically where 457 energy levels are calculated. A highly energetic electrons are considered as the main pumping source for the population of the energy levels. Relativistic calculations are considered through the calculations and the possible X-ray laser transitions are determined with their gain coefficients. The soft $\mathrm{X}$-ray laser transitions $(\lambda \approx 17-27 \mathrm{~nm})$ are dominant by the magnetic quadrupole M2. The results show good agreement with the observed data and moreover, new transitions that are not given in literatures are calculated together with their gain values.
\end{abstract}

Keywords. Soft X-ray lasers, Neon like arsenic, Magnetic quadrupole, Fully relativistic energy levels, Distorted waves, Gain coefficients. 


\section{Introduction}

The collisional excitation of atoms was first proposed by Hagelstein[1, 2]. Hagelstein proposed that when a high energetic beam of radiation falls on a thin foil of a solid target then the outer electrons can easily collide with target plasma. In that case an inner electrons are excited to a higher energy levels through electron collisions. Once the population inversion occurs through different energy levels, a short laser wavelengths are emitted. The amplification of short laser wavelengths (X-ray lasers) occurs during a single pass scince the normal glass mirrors are transparent to such kind of lasers. X-ray lasers are amplified through the amplified spontaneous emission (ASE).

Experimentally, X-ray laser emission was first detected in 1972 [3] by using a pulsed Q-switched Nd:glass laser as a pumping source. In 1985, a theoretical and experimental work were carried out on selenium [4] to prove the emission of neon-like selenium laser radiation with 20.63 and $20.96 \mathrm{~nm}$ and a gain coefficients $5.5 \mathrm{~cm}^{-1}$. Since 1985 , many experiments were done $[5$, $6,7,8,9,10,11,12,13]$ on different targets to get shorter wavelengths and higher gain coefficients.

To our knowledge the neon like Arsenic was not theoretically calculated although an emitted X-ray laser emission was experimentally observed [14]. In this article a fully relativistic calculation of energy levels was done. Using the distorted wave (DW) approximations the effective collision strengths were calculated. The collisional radiative model was applied to calculate the population of the energy levels and subsequently evaluating the gain coefficients. The flexible atomic code, FAC v1.1.3 is used through our calculations $[15]$.

\section{Dirac equation}

The atomic data are calculated using Dirac equation $\mathcal{H} \Psi=E \Psi$ where $\mathcal{H}$ is the Dirac-Coulomb Hamiltonian for atoms or ions with N-electrons, in atomic units, expressed as

$$
\mathcal{H}=\sum_{i}^{N} H_{D}^{i}+\sum_{j>i}^{N} \frac{1}{r_{i j}},
$$

where $H_{D}^{i}$ is the Dirac Hamiltonian for the $i^{\text {th }}$ electron and the second term is the interaction term between electrons. The configuration state functions $\psi$ consists of the antisymetric sums of products of $\mathrm{N}$ one-electron Dirac spinors 
$\varphi_{n \kappa m}$

$$
\varphi(r, \theta, \phi, \sigma)=\frac{1}{r}\left(\begin{array}{c}
P(r) \chi_{\kappa}^{j}(\theta, \phi, \sigma) \\
i Q(r) \chi_{-\kappa}^{j}(\theta, \phi, \sigma)
\end{array}\right),
$$

where $P(r)$ and $Q(r)$ are functions of $r$ only and $\chi_{\kappa}^{j}$ is spherical harmonics that depends on the angular coordinates $(\theta, \phi)$ and the spin $\sigma$.

The atomic wave function $\Psi$ can be constructed by the configuration states $\psi$ with the symmetries as

$$
\Psi=\sum_{i} b_{i} \psi_{i}
$$

where $b_{i}$ are the mixing coefficients obtained by diagonalizing the Hamiltonian.

The line strength $S_{j i}$ of any transition is given by [15]

$$
S_{j i}=\left|\left\langle\Psi_{j}\left|O_{L M}\right| \Psi_{i}\right\rangle\right|^{2},
$$

where $L$ is the multipole rank type. The weighted oscillator strength $g f_{j i}$ is defined as

$$
g f_{j i}=(2 L+1)^{-1} \omega(\alpha \omega)^{2 L-2} S_{j i}
$$

where $\omega$ is the transition energy in amu, $\alpha$ is the fine structure constant and $g$ is the statistical weight. The radiative transition rates for allowed electric dipole transitions $A_{j i}$ are given by [16]

$$
g A_{j i}=2(\alpha \omega)^{3} g f_{j i},
$$

while the transition rates for electric quadrupole E2 are given by [16]

$$
g_{j} A_{j i}=2.67733 \times 10^{3} \omega^{5} S_{i j}^{E 2} .
$$

The transition rates for magnetic dipoles M1 are given by [16]

$$
g_{j} A_{j i}=3.5644 \times 10^{4} \omega^{3} S_{i j}^{M 1},
$$

while the transition rates for magnetic quadrupoles M2 are given by [16]

$$
g_{j} A_{j i}=2.3727 \times 10^{-2} \omega^{5} S_{i j}^{M 2} .
$$

\section{Electron impact excitations}

In electron impact excitation we consider an incident beam of electrons collide with a target ion or atom. The electron interaction with the target are either 
elastic scattering with no change of energy or inelastic scattering with a net change of energy.

If the scattered electrons have a solid angle $d \omega=\sin \theta d \theta d \phi$, then the differential cross section is defined as

$$
\frac{d \sigma}{d \omega}=|f(\theta, \phi)|^{2}
$$

where $f(\theta, \phi)$ is the scattering amplitude function, the total cross section is defined as

$$
\sigma=\int \frac{d \sigma}{d \omega} d \omega
$$

The scattering amplitude function $f(\theta, \phi)$ gives us the probability of the scattering electron in a certain directions $(\theta, \phi)$ and could be calculated with different techniques; either by the differential form as in the partial wave analysis or by the integral form as in the Born approximations [17].

\subsection{Distorted wave approximations}

There are many techniques to calculate the scattering amplitude function using the integral form, the most famous technique is the close coupling or R-matrix. In the distorted wave approximations (DW) we could express the wavefunction of the scattering system as

$$
\psi_{s}(r, \theta) \approx e^{-i \vec{k} \cdot \vec{r}}+\frac{1}{r} e^{i k r} f(\theta, \phi) .
$$

The scattering amplitude function is expressed as [18]

$$
f(\theta, \phi)=-\frac{1}{4 \pi} \frac{2 m}{\hbar^{2}} \int \Psi^{*}\left(r^{\prime}\right)\left(V\left(r^{\prime}\right) \Psi\left(r^{\prime}\right) \pm \int K\left(r, r^{\prime}\right) \Psi(r) d r\right) d r^{\prime},
$$

where $r^{\prime}$ is the coordinate outside the scattering region, $r$ is the coordinate in the scattering region and $\Psi^{*}\left(r^{\prime}\right)$ is the complex conjugate. $K\left(r, r^{\prime}\right)$ is a function in the form

$$
K\left(r, r^{\prime}\right)=\Psi\left(r^{\prime}\right) \Psi^{*}(r)\left(\frac{e^{2}}{\left|r-r^{\prime}\right|}+E+\Delta E\right),
$$

where $E$ is the energy of the incident electron and $\Delta E$ is the energy gained by the target system. Scattering amplitude represented by equation (13) is called the distorted wave (DW) expression and it doesn't take the interaction terms between the incident and target electrons into account. 


\subsection{Collision strength $\Omega_{i j}$}

We could express the collision strength of the collisional processes in terms of the cross section $\sigma$ as

$$
\sigma_{i j}=\frac{\Omega_{i j}}{g_{i} k_{i}^{2}}\left(\pi a_{0}^{2}\right)
$$

where $\Omega_{i j}$ is the collisional collision strength of the transition $i-j, g_{i}$ is the statistical weight of the state $i, E=k_{i}^{2}$ is the incident electron energy, $a_{0}$ is the Bohr radius and $\pi a_{0}^{2}$ is the cross section of the hydrogen atom.

\subsection{Excitation rate coefficients}

Practically the cross section averaged over the velocity distribution of the scattered electrons is very important and is called the rate coefficient and has the form

$$
C_{j i}^{d}=<\sigma v>=\int_{0}^{\infty} \sigma_{j i}(E) v(E) f(E) d E,
$$

as a function of energy.

Assuming that the scattered electrons have a Maxwellian distribution then we get

$$
C_{j i}^{d}=\frac{h^{2}}{8 \pi m g_{j}} \sqrt{\frac{2}{m}} \frac{2}{\sqrt{\pi}\left(k T_{e}\right)^{3 / 2}} \int_{0}^{\infty} \Omega_{j i}(E) e^{-E / k T_{e}} d E,
$$

where the integral usually defined as the effective collision strength $\gamma_{j i}$ is

$$
\gamma_{j i}=\int_{0}^{\infty} \Omega_{j i}(E) e^{-E / k T_{e}} d\left(\frac{E}{k T_{e}}\right)
$$

where it is the Maxwellian average of the collision strength. Equation (17) becomes

$$
\begin{aligned}
C_{j i}^{d} & =\frac{2 h^{2}}{8 \pi m} \sqrt{\frac{2}{\pi m}} \frac{1}{g_{j} \sqrt{T_{e}}} \gamma_{j i} \\
& =\frac{8.6287 \times 10^{-6}}{g_{j} \sqrt{T_{e}}} \gamma_{j i} \text { in cgs units }\left(\mathrm{cm}^{3} / \mathrm{s}\right),
\end{aligned}
$$

where $C_{j i}^{d}$ is the collisional de-excitation rate expressed as a function of the effective collision strength $\gamma_{j i}$, the statistical weight $g_{j}$ of the upper state and the electron temperature $T_{e}$. By the same way the excitation rate coefficient $C_{i j}^{e}$ could be expressed as [19]

$$
C_{i j}^{e}=\frac{8.6287 \times 10^{-6}}{g_{i} \sqrt{T_{e}}} e^{-E_{j i} / k T_{e}} \gamma_{j i} \quad \text { in cgs units }\left(\mathrm{cm}^{3} / \mathrm{s}\right)
$$


where $E_{j i}$ is the energy difference between the initial and final states of the transitions. In the derivation we have used $\left(\Omega_{i j} \approx \Omega_{j i}\right)$ and subsequently $\left(\gamma_{i j} \approx \gamma_{j i}\right)$. Both excitation and de-excitation rates could be expressed as

$$
C_{j i}^{d}=C_{i j}^{e} \frac{g_{i}}{g_{j}} e^{E_{j i} / k T_{e}}
$$

\section{$4 \quad$ Energy level populations}

Taking the electron collisions as the main mechanism for the population of states (energy levels) then we could define our rate equation to be

$$
\frac{d n_{i}}{d t}=-n_{i} \sum_{\substack{j \neq i \\ j>i}}^{l} n_{e} C_{i j}^{e}+\sum_{\substack{j \neq i \\ j>i}}^{l} n_{j}\left(A_{j i}+n_{e} C_{j i}^{d}\right)
$$

where $C_{i j}^{e}$ and $C_{j i}^{d}$ are the excitation and deexcitation rates respectively. Solving equation (22) for the quasi steady states $\frac{d n_{i}}{d t}=0$, and finding the population $n_{i}$.

In order to determine the population of states other than the trivial solution we need a more boundary condition to our model which is to determine the total number of atoms $N_{a}$, and to do that we use the same properties of the first experiment of the neon like Selenium [4]. In that experiment a collimated beam of high power laser was cocenterated on a cylinderical target with length $1.2 \mathrm{~cm}$ and $200 \mu \mathrm{m}$ in diameters [20,21]. using the ratio of the ion temperature $T_{i}$ to the electron temperature $T_{e}$ to be $0.4[22,23]$. Five electron temperatures $T_{e}$ were taken into our calculations.

The total number of atoms $N_{a}$ could be determined as

$$
N_{a}=\frac{\rho V}{A},
$$

where $\rho$ is the target density, $V$ is the volume of the target plasma and $A$ is the atomic weight of the atoms. The ion fraction $N_{I}$ can be expressed as $N_{I}=f N_{a}$ where $f$ is the fraction of the neon like atoms that was produced in the plasma and was taken to be $6 \times 10^{-5}$. Equation 22 were solved using our code written in python language.

\section{Gain coefficients}

Gain coefficient $g(\nu)$ is related to the cross section $\sigma$ as follow

$$
g(\nu)=N_{j} \sigma_{s}-N_{i} \sigma_{a}=N_{j} \sigma_{s} \mathcal{F},
$$


where $\mathcal{F}$ is the population inversion factor and can be expressed as

$$
\mathcal{F}=1-\frac{N_{i}}{N_{j}} \frac{\sigma_{a}}{\sigma_{s}}=1-\frac{N_{i}}{N_{j}} \frac{g_{j}}{g_{i}}
$$

where $\sigma_{s}$ and $\sigma_{a}$ are the stimulated and the absorption cross sections, $N_{i}$ and $N_{j}$ are the population densities of states $|i\rangle$ and $|j\rangle$ respectively and $g_{i}$ and $g_{j}$ are the statistical weights of states $|i\rangle$ and $|j\rangle$ respectively.

Due to the Doppler effect, the spectral line wavelength is broadened and then due to Doppler effect the wavelength is expressed [24] as

$$
\frac{\Delta \lambda_{D}}{\lambda}=\frac{2 \sqrt{2 \ln 2}}{c} \sqrt{\frac{k T_{i}}{M_{i}}}
$$

where $\Delta \lambda_{D}$ is the FWHM which is due to the Doppler broadening, $k T_{i}$ is the kinetic energy of the ions in $\mathrm{eV}$ and $M_{i}$ is the ion atomic mass.

Taking Doppler broadening as the main mechanism of brodening in X-ray lasers $[23,25,26]$ then the gain coefficient $g(\nu)$ can be given by [27]

$$
g^{D}(\nu)=\frac{\lambda^{3}}{8 \pi \eta^{3}} g_{j} A_{j i} \sqrt{\frac{M_{i}}{2 \pi k T_{i}}}\left(\frac{N_{j}}{g_{j}}-\frac{N_{i}}{g_{i}}\right),
$$

where $\lambda=\frac{c}{\nu \eta}$ is the transition wavelength, $\eta$ is the refractive index $\eta=$ $\sqrt{1-\frac{n_{e}}{n_{c}}}$ where $n_{c}=\frac{\epsilon_{0} m_{e}}{e^{2}}(2 \pi \nu)^{2}, g_{i}$ and $g_{j}$ are the statistical weights of the lower and upper levels respectively, $A_{j i}$ is the transition rate, $M_{i}$ is the ion mass, $T_{i}$ is the ion temperature and $N_{i}$ and $N_{j}$ are the lower and upper level populations.

\section{Results and discussions}

\subsection{Energy levels of Ne-like Arsenic $\mathrm{As}^{+23}$}

By comparing our data with the available 21 levels given by $\mathrm{NIST}^{1}$, table 1 , we could find that most of our data have discrepancies ${ }^{2}$ less that $0.1 \%$ except for levels index $\left(2 ;\left(2 p_{3 / 2} 3 s_{1 / 2}\right)_{J=1}^{o}\right),\left(46 ;\left(2 p_{1 / 2} 4 s_{1 / 2}\right)_{J=1}^{o}\right)$ and $\left(96 ;\left(2 p_{3 / 2} 5 d_{5 / 2}\right)_{J=1}^{o}\right)$ which have discrepancies $0.16 \%$. Also $\left(188 ;\left(2 p_{1 / 2} 6 d_{3 / 2}\right)_{J=1}^{o}\right)$ and $\left(130 ;\left(2 p_{1 / 2} 5 d_{3 / 2}\right)_{J=1}^{o}\right)$ levels have discrepancies $0.2 \%$. Generally our calculations are in an excellent agreement with the NIST values for the energy levels of Neon like Arsenic ions.

\footnotetext{
${ }^{1}$ NIST is abbreviation of the National Institute of Standards and Technology and it provides the most accurate data that was proved either theoretically or experimentally.

${ }^{2}$ discrepancy $(\%)=\left|\frac{\text { calculated value-reference value }}{\text { reference value }}\right| \times 100 \%$
} 


\begin{tabular}{|ccccl|}
\hline index & level designation & $J^{\pi}$ & $E_{\text {calculated }}(\mathrm{eV})$ & $E_{N I S T}(\mathrm{eV})[28]$ \\
\hline \hline 0 & $2 p^{6}$ & $0^{e}$ & 0.00 & 0.0 \\
2 & $2 p_{3 / 2} 3 s_{1 / 2}$ & $1^{o}$ & 1335.48 & 1337.6655 \\
4 & $2 p_{1 / 2} 3 s_{1 / 2}$ & $1^{o}$ & 1371.33 & 1372.3811 \\
16 & $2 p_{3 / 2} 3 d_{3 / 2}$ & $1^{o}$ & 1446.38 & 1447.2675 \\
22 & $2 p_{3 / 2} 3 d_{5 / 2}$ & $1^{o}$ & 1464.48 & 1464.8733 \\
26 & $2 p_{1 / 2} 3 d_{3 / 2}$ & $1^{o}$ & 1498.40 & 1498.9689 \\
30 & $2 s_{1 / 2} 3 p_{1 / 2}$ & $1^{o}$ & 1585.30 & 1583.6502 \\
32 & $2 s_{1 / 2} 3 p_{3 / 2}$ & $1^{o}$ & 1595.90 & 1594.1888 \\
38 & $2 p_{3 / 2} 4 s_{1 / 2}$ & $1^{o}$ & 1804.91 & 1807.0697 \\
46 & $2 p_{1 / 2} 4 s_{1 / 2}$ & $1^{o}$ & 1841.71 & 1844.6369 \\
48 & $2 p_{3 / 2} 4 d_{3 / 2}$ & $1^{o}$ & 1848.60 & 1850.8361 \\
54 & $2 p_{3 / 2} 4 d_{5 / 2}$ & $1^{o}$ & 1855.59 & 1857.1593 \\
70 & $2 p_{1 / 2} 4 d_{3 / 2}$ & $1^{o}$ & 1890.28 & 1892.6188 \\
86 & $2 s_{1 / 2} 4 p_{1 / 2}$ & $1^{o}$ & 2026.05 & 2026.8937 \\
88 & $2 s_{1 / 2} 4 p_{3 / 2}$ & $1^{o}$ & 2030.03 & 2030.4892 \\
90 & $2 p_{3 / 2} 5 d_{3 / 2}$ & $1^{o}$ & 2032.45 & 2030.4892 \\
96 & $2 p_{3 / 2} 5 d_{5 / 2}$ & $1^{o}$ & 2035.71 & 2038.9201 \\
130 & $2 p_{1 / 2} 5 d_{3 / 2}$ & $1^{o}$ & 2071.62 & 2075.7434 \\
148 & $2 p_{3 / 2} 6 d_{3 / 2}$ & $1^{o}$ & 2131.33 & 2133.6441 \\
154 & $2 p_{3 / 2} 6 d_{5 / 2}$ & $1^{o}$ & 2133.22 & 2137.2396 \\
188 & $2 p_{1 / 2} 6 d_{3 / 2}$ & $1^{o}$ & 2169.75 & 2174.8068 \\
\hline
\end{tabular}

Table 1: Energy levels of neon-like arsenic ions $A s^{+23}$. The index column represents the index of each energy level from 0 to 456

\subsection{Gain coefficient $g(\nu)$ of Ne-like Arsenic $A s^{+23}$}

In order to evaluate the gain coefficients we calculated the population inversion factors $\mathcal{F}$, Doppler broadening $\lambda_{D}$ and the effective collision strengths $\gamma_{j i}$.

The population inversion of the highest five gain lines at five electron temperatures $T_{e}=500,700,1000,1500$ and $1900 \mathrm{eV}$ are shown in figure 1 . The behavior of the population inversion $\mathcal{F}$ could be explained by the following : By increasing the electron density $n_{e}$ in the plasma system, we have a more possible electrons that could populate a higher energy levels and in that case the population of the higher states $N_{j}$ increases by time and we could say that the inequality $N_{j}>N_{i}$ holds. In that case the population inversion factor $\left(\mathcal{F}=1-\frac{N_{i} g_{j}}{N_{j} g_{i}}\right)$ increases and the main mechanism that cause lowering 
the population of the higher state levels is the radiative transition rates $A_{j i}$. By increasing the electron density $n_{e}$ the electron collisions between electrons can not be neglected and the collisional excitaion $\Omega_{i j}$, collisional de-excitation $\Omega_{j i}$ where $\left(\Omega_{j i}=\Omega_{i j}\right)$ and the effective collision strength strength $\left(\gamma_{i j}=\gamma_{j i}\right)$ increases. By increasing of $\gamma_{i j}$ makes the collisional de-excitation more dominant $C_{j i}^{d}$ than the collisional excitaion $C_{i j}^{e}$ (see equations (19),(20)). As the collisional de-excitation rates become dominant at higher electron densities, that makes the population of the higher states decreases and the population inversion factor $\mathcal{F}$ decreases again.

The maximum value of the population inversion $\mathcal{F}$ corresponds to the equality of the collisional de-excitation $C_{j i}^{d}$ and the radiative transition rates $A_{j i}$.

Doppler broadening of the highest transition lines in neon-like arsenic ions are in table 2. The table indicates that the shortest wavelengths appears in an electron temperatures $T_{e} \leq 1000 \mathrm{eV}$ and by increasing the electron temperatures we get a higher wavelength transitions.

The effective collision strength of the highest gain transitions are shown in figure 2.

Gain coefficients of the highest five transitions at five electron temperatures are shown in figure 3. Gain coefficients could be explained as: gains $g(\nu)$ are directly proportional to the population inversions $\mathcal{F}$ (see equation 27) so gains are related to the electron densities $n_{e}$ by the same behavior as the population inversion.

\subsection{Shortest wavelengths that appear in the Ne-like arsenic $\mathrm{As}^{+23}$ with gain coefficient $g(\nu) \geq 1$}

All wavelengths with their gain $g(\nu)$ at five different electron plasma temperatures $\left(T_{e}=500,700,1000,1500\right.$ and $\left.1900 \mathrm{eV}\right)$ for $A s^{+23}$ ions are in table 3.

In neon like Arsenic ions $A s^{+23}$, the following line transitions [14] (92)and $(13-4)$ are observed with gains $5.4 \mathrm{~cm}^{-1}$ which agrees with our calculations as seen in table (3).

\section{Conclusion}

The atomic data of the neon-like arsenic were calculated relativistically and the electron collisional excitation model was applied to calculate the population of 457 energy levels of the $A s^{+23}$ ions. The rate equations were solved and all gains greater than 1 were determined for all the possible transitions. 


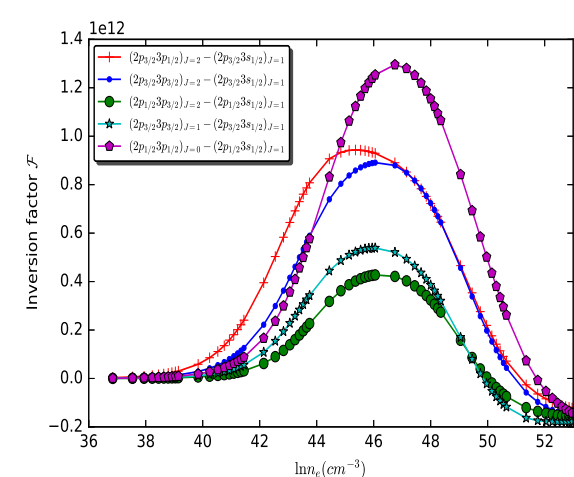

(a) Population inversion of the Nelike As at electron plasma temperatures $T_{e}=500 \mathrm{eV}$.

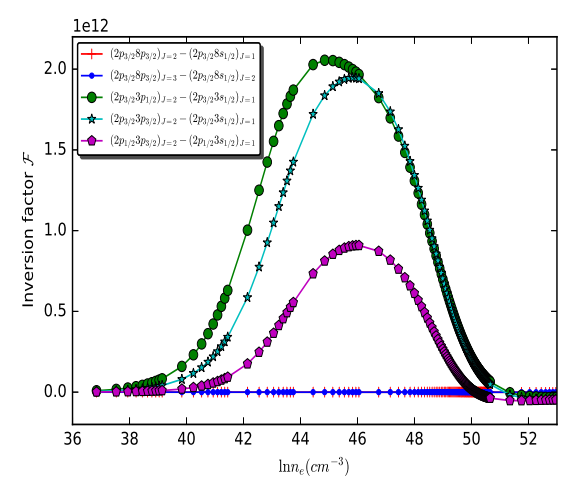

(c) Population inversion of the Nelike As at electron plasma temperatures $T_{e}=1000 \mathrm{eV}$.

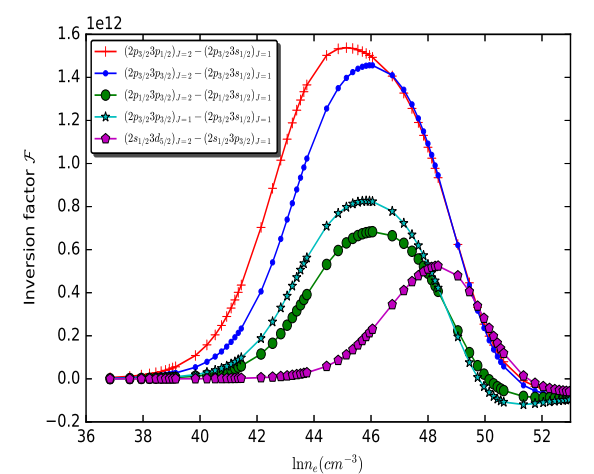

(b) Population inversion of the Nelike As at electron plasma temperatures $T_{e}=700 \mathrm{eV}$.

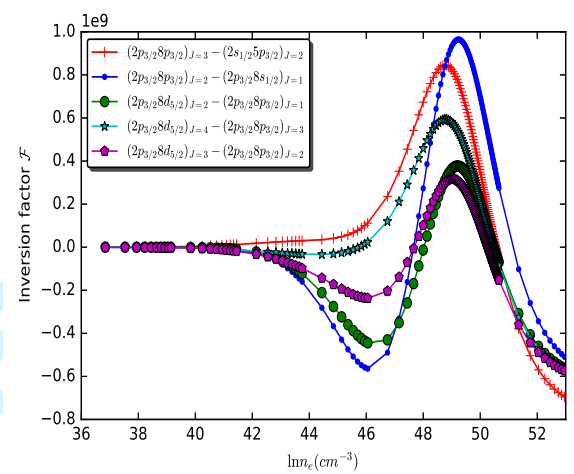

(d) Population inversion of the Nelike As at electron plasma temperatures $T_{e}=1500 \mathrm{eV}$.

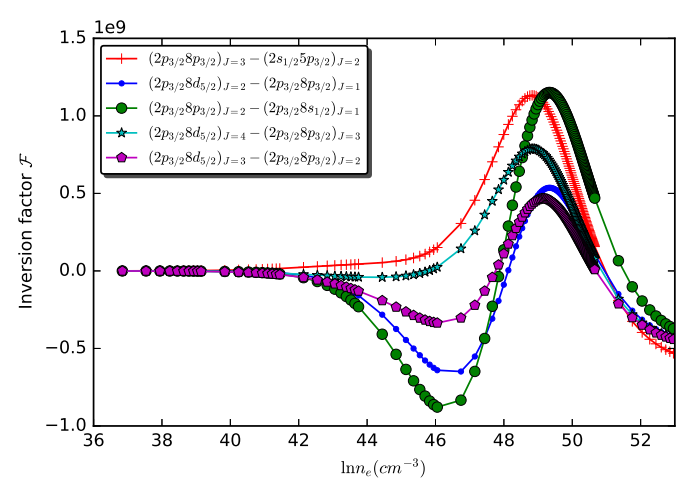

(e) Population inversion of the Nelike As at electron plasma temperatures $T_{e}=1900 \mathrm{eV}$.

Figure 1: Population inversion for neon-like arsenic ions $A s^{+23}$ at five electron temperatures $T_{e}$. 


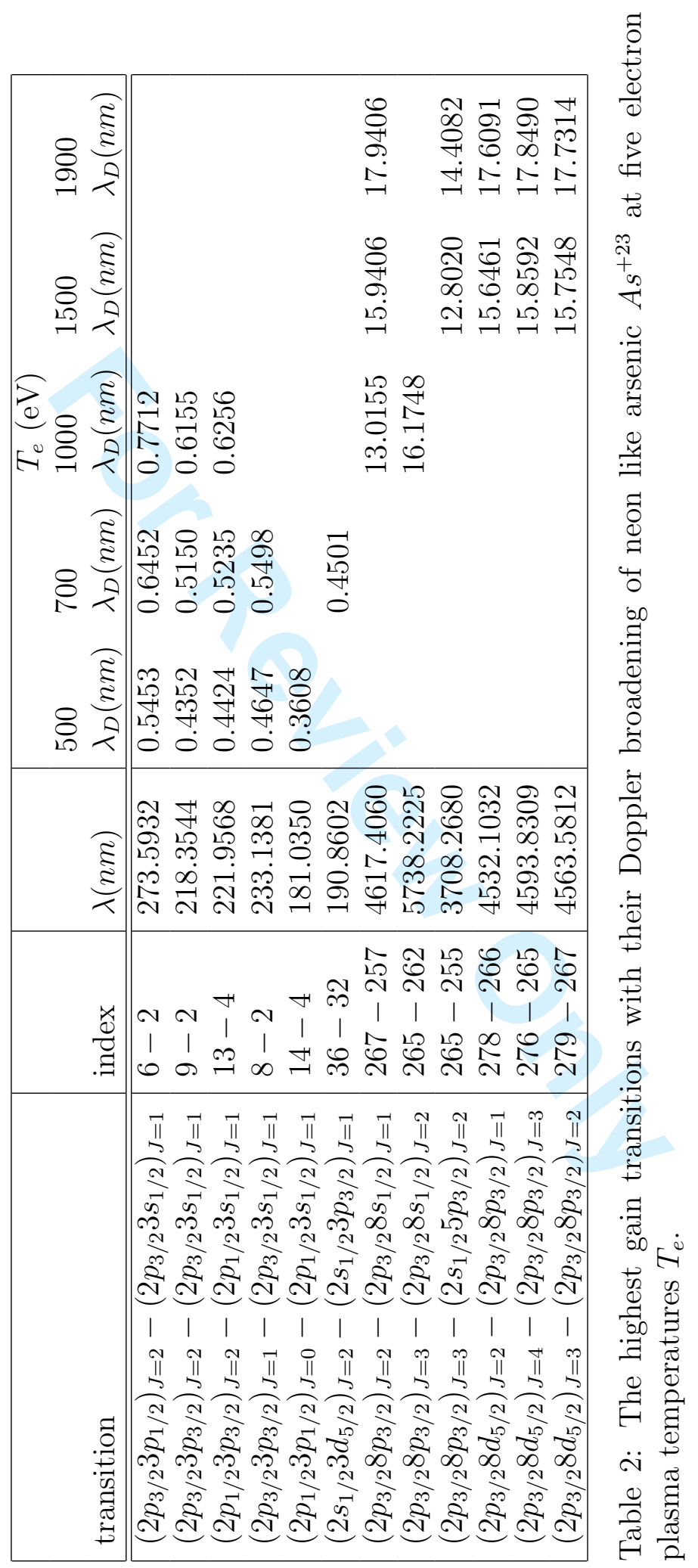




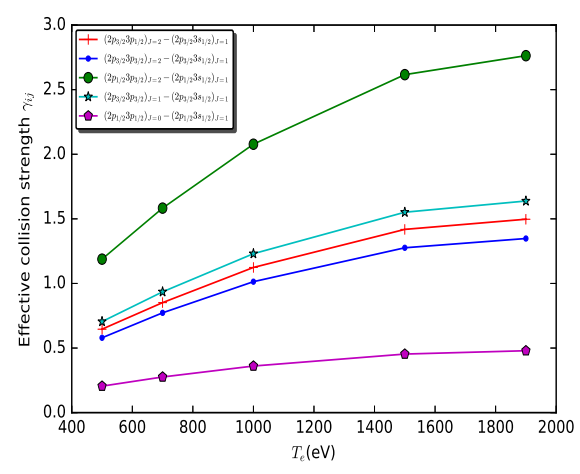

(a) Effective collision strengths of Nelike As at $T_{e}=500 \mathrm{eV}$.

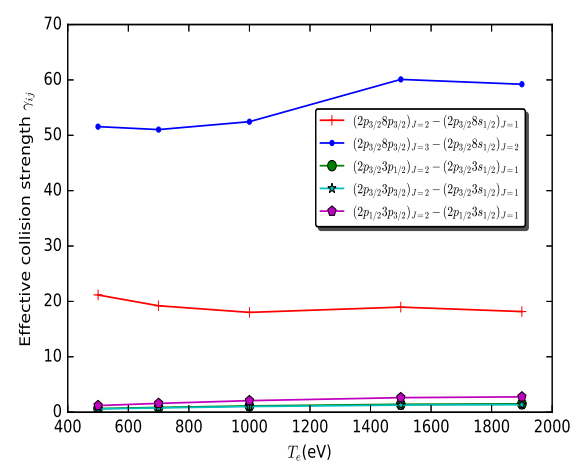

(c) Effective collision strengths of Nelike As at $T_{e}=1000 \mathrm{eV}$.

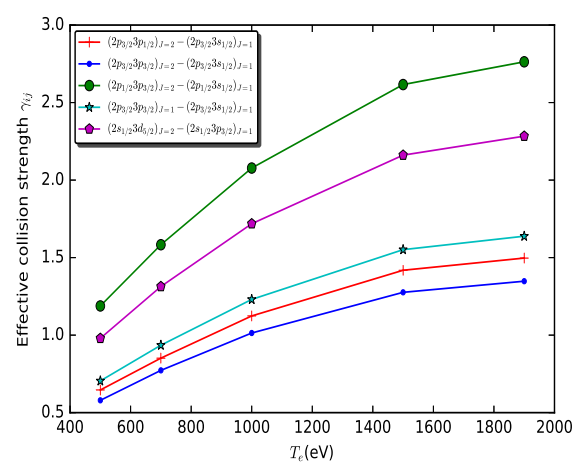

(b) Effective collision strengths of Ne-like As at $T_{e}=700 \mathrm{eV}$.

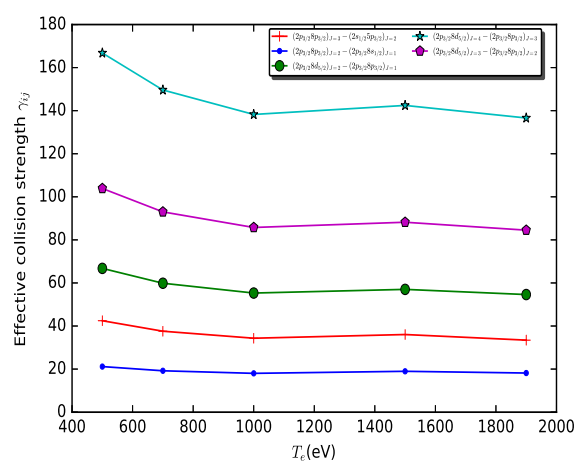

(d) Effective collision strengths of Ne-like As at $T_{e}=1500 \mathrm{eV}$.

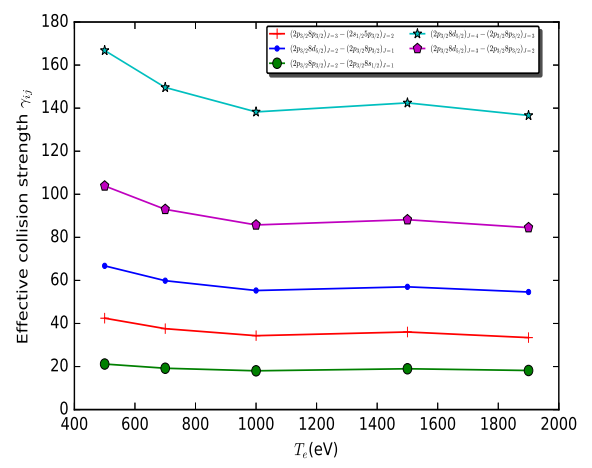

(e) Effective collision strengths of Nelike As at $T_{e}=1900 \mathrm{eV}$.

Figure 2: Effective collision strengths of the highest gain transitions at five electron temperatures $T_{e}$ for neon-like arsenic ions $\mathrm{As}^{+23}$. 


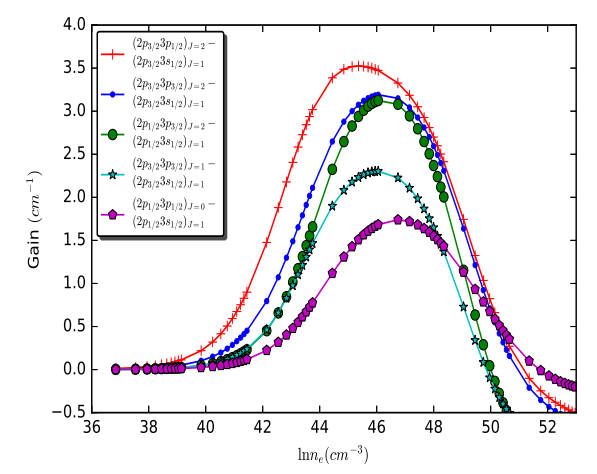

(a) Gain coefficients of Ne-like As at $T_{e}=500 \mathrm{eV}$.

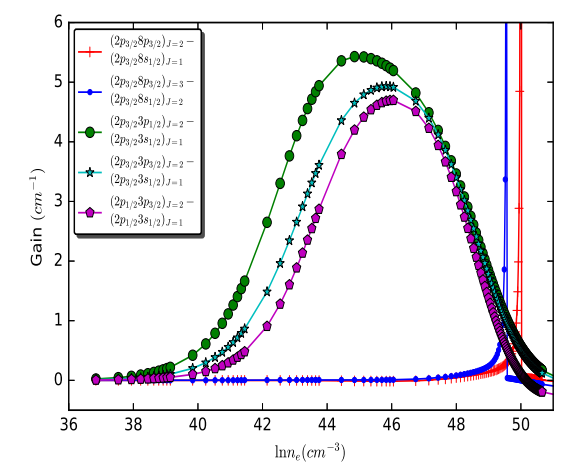

(c) Gain coefficients of Ne-like As at $T_{e}=1000 \mathrm{eV}$.

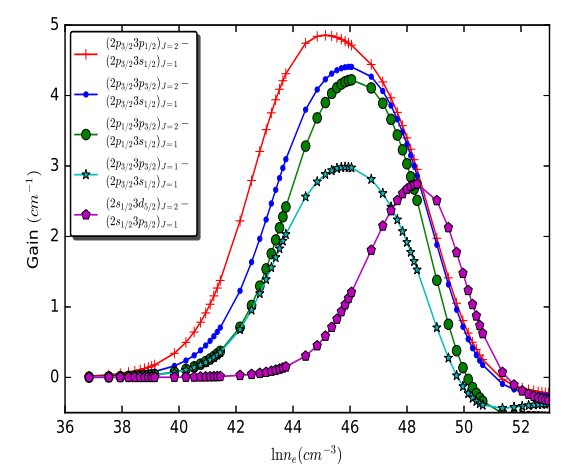

(b) Gain coefficients of Ne-like As at $T_{e}=700 \mathrm{eV}$.

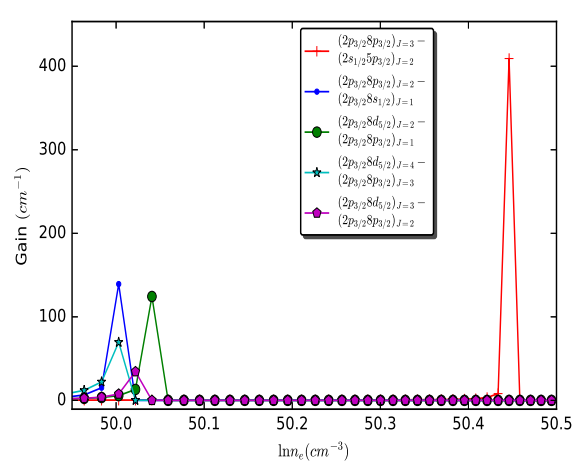

(d) Gain coefficients of Ne-like As at $T_{e}=1500 \mathrm{eV}$.

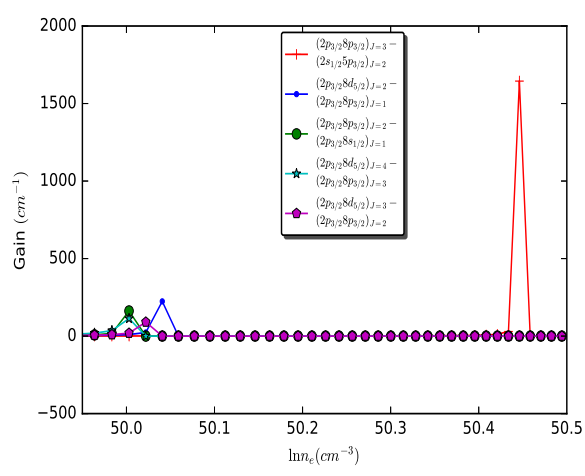

(e) Gain coefficients of Ne-like As at $T_{e}=1900 \mathrm{eV}$.

Figure 3: Gain coefficient for five transitions at five electron temperatures $T_{e}$ for neon-like arsenic ions $A s^{+23}$. 


\begin{tabular}{|c|c|c|c|c|c|c|c|c|c|}
\hline \multirow[b]{2}{*}{ index } & \multirow[b]{2}{*}{ transition } & \multirow[b]{2}{*}{ type } & \multirow[b]{2}{*}{$\lambda(n m)$} & \multirow[b]{2}{*}{ G-E } & \multicolumn{5}{|c|}{$T_{e}(\mathrm{eV})$} \\
\hline & & & & & 500 & 700 & 1000 & 1500 & 1900 \\
\hline$(10-2)$ & $\begin{array}{l}\left(2 p_{3 / 2} 3 p_{3 / 2}\right)_{J=0^{-}}^{e} \\
\left(2 p_{3 / 2} 3 s_{1 / 2}\right)_{J=1}^{o}\end{array}$ & E1 & 17.846 & $\begin{array}{l}g(\nu) \\
n_{e}\end{array}$ & & & & $\begin{array}{l}1.04 \\
6.0(19)\end{array}$ & $\begin{array}{l}1.07 \\
6.0(19)\end{array}$ \\
\hline$(14-4)$ & $\begin{array}{l}\left(2 p_{1 / 2} 3 p_{1 / 2}\right)_{J=0^{e}}^{e} \\
\left(2 p_{1 / 2} 3 s_{1 / 2}\right)_{J=1}^{O}\end{array}$ & E1 & 18.103 & $\begin{array}{l}g(\nu) \\
n_{e}\end{array}$ & $\begin{array}{l}1.74 \\
2.0(20)\end{array}$ & $\begin{array}{l}2.53 \\
2.0(20)\end{array}$ & $\begin{array}{l}3.04 \\
1.0(20)\end{array}$ & $\begin{array}{l}3.29 \\
1.0(20)\end{array}$ & $\begin{array}{l}3.33 \\
1.0(20)\end{array}$ \\
\hline$(34-30)$ & $\begin{array}{l}\left(2 s_{1 / 2} 3 d_{3 / 2}\right)_{J=2}^{e}- \\
\left(2 s_{1 / 2} 3 p_{1 / 2}\right)_{J=1}^{O}\end{array}$ & $\begin{array}{l}\text { E1 } \\
\text { M2 } \\
\end{array}$ & 18.496 & $\begin{array}{l}g(\nu) \\
n_{e} \\
\end{array}$ & & & $\begin{array}{l}1.15 \\
5.0(20)\end{array}$ & $\begin{array}{l}1.12 \\
5.0(20)\end{array}$ & $\begin{array}{l}1.14 \\
5.0(20)\end{array}$ \\
\hline$(36-32)$ & $\begin{array}{l}\left(2 s_{1 / 2} 3 d_{5 / 2}\right)_{J=2}^{e}- \\
\left(2 s_{1 / 2} 3 p_{3 / 2}\right)_{J=1}^{o}\end{array}$ & $\begin{array}{l}\text { E1 } \\
\text { M2 }\end{array}$ & 19.086 & $\begin{array}{l}g(\nu) \\
n_{e}\end{array}$ & $\begin{array}{l}1.66 \\
2.0(21)\end{array}$ & $\begin{array}{l}2.75 \\
1.0(21) \\
\end{array}$ & $\begin{array}{l}3.68 \\
8.0(20) \\
\end{array}$ & $\begin{array}{l}4.32 \\
6.0(20) \\
\end{array}$ & $\begin{array}{l}4.5 \\
6.0(20) \\
\end{array}$ \\
\hline$(20-8)$ & $\begin{array}{l}\left.\left(2 p_{3 / 2} 3 d_{3 / 2}\right)^{o}\right)_{J=2}^{-} \\
\left(2 p_{3 / 2} 3 p_{3 / 2}\right)_{J=1}^{e}\end{array}$ & E1 & 19.295 & $\begin{array}{l}g(\nu) \\
n_{e}\end{array}$ & & & $\begin{array}{l}1.22 \\
3.0(20)\end{array}$ & $\begin{array}{l}1.29 \\
2.0(20)\end{array}$ & $\begin{array}{l}.31 \\
2.0(20)\end{array}$ \\
\hline$(9-2)$ & $\begin{array}{l}\left(2 p_{3 / 2} 3 p_{3 / 2}\right)_{J=2}^{e}- \\
\left(2 p_{3 / 2} 3 s_{1 / 2}\right)_{J=1}^{o}\end{array}$ & $\begin{array}{l}\text { E1 } \\
\text { M2 }\end{array}$ & 21.835 & $\begin{array}{l}g(\nu) \\
n_{e}\end{array}$ & $\begin{array}{l}3.19 \\
1.0(20)\end{array}$ & $\begin{array}{l}4.41 \\
9.0(19)\end{array}$ & $\begin{array}{l}4.93 \\
8.0(19)\end{array}$ & $\begin{array}{l}4.71 \\
8.0(19)\end{array}$ & $\begin{array}{l}4.65 \\
8.0(19)\end{array}$ \\
\hline$(13-4)$ & $\begin{array}{l}\left(2 p_{1 / 2} 3 p_{3 / 2}\right)_{J=2}^{e}- \\
\left(2 p_{1 / 2} 3 s_{1 / 2}\right)_{J=1}^{O}\end{array}$ & $\begin{array}{l}\text { E1 } \\
\text { M2 }\end{array}$ & 22.196 & $\begin{array}{l}g(\nu) \\
n_{e}\end{array}$ & $\begin{array}{l}3.12 \\
1.0(20)\end{array}$ & $\begin{array}{l}4.22 \\
1.0(20)\end{array}$ & $\begin{array}{l}4.7 \\
1.0(20)\end{array}$ & $\begin{array}{l}4.6 \\
9.0(19)\end{array}$ & $\begin{array}{l}4.63 \\
9.0(19)\end{array}$ \\
\hline$(12-4)$ & $\begin{array}{l}\left(2 p_{1 / 2} 3 p_{3 / 2}\right)_{J=1}^{e}- \\
\left(2 p_{1 / 2} 3 s_{1 / 2}\right)_{J=1}^{o}\end{array}$ & $\begin{array}{l}\text { E1 } \\
\text { M2 }\end{array}$ & 22.63 & $\begin{array}{l}g(\nu) \\
n_{e}\end{array}$ & & $\begin{array}{l}1.22 \\
8.0(19)\end{array}$ & $\begin{array}{l}1.31 \\
7.0(19)\end{array}$ & $\begin{array}{l}1.19 \\
7.0(19)\end{array}$ & $\begin{array}{l}1.15 \\
7.0(19)\end{array}$ \\
\hline$(8-2)$ & $\begin{array}{l}\left(2 p_{3 / 2} 3 p_{3 / 2}\right)_{J=1}^{e}- \\
\left(2 p_{3 / 2} 3 s_{1 / 2}\right)_{J=1}^{o}\end{array}$ & $\begin{array}{l}\text { E1 } \\
\text { M2 } \\
\end{array}$ & 23.314 & $\begin{array}{l}g(\nu) \\
n_{e}\end{array}$ & $\begin{array}{l}2.3 \\
1.0(20) \\
\end{array}$ & $\begin{array}{l}2.98 \\
8.0(19)\end{array}$ & $\begin{array}{l}3.2 \\
7.0(19) \\
\end{array}$ & $\begin{array}{l}3.02 \\
6.0(19)\end{array}$ & $\begin{array}{l}3.01 \\
6.0(19)\end{array}$ \\
\hline$(11-4)$ & $\begin{array}{l}\left(2 p_{1 / 2} 3 p_{1 / 2}\right)_{J=1}^{e}- \\
\left(2 p_{1 / 2} 3 s_{1 / 2}\right)_{J=1}^{o}\end{array}$ & $\begin{array}{l}\text { E1 } \\
\text { M2 }\end{array}$ & 27.192 & $\begin{array}{l}g(\nu) \\
n_{e}\end{array}$ & $\begin{array}{l}1.41 \\
6.0(19)\end{array}$ & $\begin{array}{l}1.85 \\
5.0(19)\end{array}$ & $\begin{array}{l}1.96 \\
5.0(19)\end{array}$ & $\begin{array}{l}1.78 \\
5.0(19)\end{array}$ & $\begin{array}{l}1.75 \\
5.0(19)\end{array}$ \\
\hline$(6-2)$ & $\begin{array}{l}\left(2 p_{3 / 2} 3 p_{1 / 2}\right)_{J=2}^{e}- \\
\left(2 p_{3 / 2} 3 s_{1 / 2}\right)_{J=1}^{o}\end{array}$ & $\begin{array}{l}\text { E1 } \\
\text { M2 }\end{array}$ & 27.359 & $\begin{array}{l}g(\nu) \\
n_{e}\end{array}$ & $\begin{array}{l}3.52 \\
5.0(19)\end{array}$ & $\begin{array}{l}4.86 \\
4.0(19)\end{array}$ & $\begin{array}{l}5.43 \\
3.0(19)\end{array}$ & $\begin{array}{l}5.21 \\
3.0(19)\end{array}$ & $\begin{array}{l}5.18 \\
3.0(19)\end{array}$ \\
\hline$(265-255)$ & $\begin{array}{l}\left(2 p_{3 / 2} 8 p_{3 / 2}\right)_{J=3}^{e}- \\
\left(2 s_{1 / 2} 5 p_{3 / 2}\right)_{J=2}^{o}\end{array}$ & E1 & 370.83 & $\begin{array}{l}g(\nu) \\
n_{e}\end{array}$ & & & & $\begin{array}{l}4.09 \mathrm{e}+02 \\
8.1(21)\end{array}$ & $\begin{array}{l}1.64 \mathrm{e}+03 \\
8.1(21)\end{array}$ \\
\hline$(268-258)$ & $\begin{array}{l}\left(2 p_{3 / 2} 8 p_{3 / 2}\right)_{J=0^{-}}^{-} \\
\left(2 s_{1 / 2} 5 p_{3 / 2}\right)_{J=1}^{o}\end{array}$ & E1 & 374.05 & $\begin{array}{c}g(\nu) \\
n_{e}\end{array}$ & & & & $\begin{array}{l}5.51 \\
7.9(21)\end{array}$ & $\begin{array}{l}10.4 \\
7.9(21)\end{array}$ \\
\hline$(275-264)$ & $\begin{array}{l}\left(2 p_{3 / 2} 8 d_{3 / 2}\right)_{J=3}^{o}- \\
\left(2 p_{3 / 2} 8 p_{1 / 2}\right)_{J=2}^{e}\end{array}$ & E1 & 408.04 & $\begin{array}{l}g(\nu) \\
n_{e}\end{array}$ & & & & $\begin{array}{l}5.41 \\
6.6(21)\end{array}$ & $\begin{array}{l}34.4 \\
6.6(21)\end{array}$ \\
\hline$(263-255)$ & $\begin{array}{l}\left(2 p_{3 / 2} 8 p_{1 / 2}\right)_{J=1}^{e}- \\
\left(2 s_{1 / 2} 5 p_{3 / 2}\right)_{J=2}^{o}\end{array}$ & E1 & 418.28 & $\begin{array}{l}g(\nu) \\
n_{e}\end{array}$ & & & & & $\begin{array}{l}4.84 \\
6.3(21)\end{array}$ \\
\hline$(436-432)$ & $\begin{array}{l}\left.\left(2 s_{1 / 2} 8 d_{5 / 2}\right)_{J=2}^{e}\right)_{J=2}^{-} \\
\left(2 s_{1 / 2} 8 p_{3 / 2}\right)_{J=1}^{o}\end{array}$ & E1 & 445.37 & $\begin{array}{l}g(\nu) \\
n_{e}\end{array}$ & & & & & $\begin{array}{l}10.1 \\
5.6(21) \\
\end{array}$ \\
\hline$(278-266)$ & $\begin{array}{l}\left.\left(2 p_{3 / 2} 8 d_{5 / 2}\right)^{o}\right)_{J=2}^{-} \\
\left(2 p_{3 / 2} 8 p_{3 / 2}\right)_{J=1}^{e}\end{array}$ & E1 & 453.21 & $\begin{array}{l}g(\nu) \\
n_{e}\end{array}$ & & & & $\begin{array}{l}1.24 \mathrm{e}+02 \\
5.4(21)\end{array}$ & $\begin{array}{l}2.24 \mathrm{e}+02 \\
5.4(21)\end{array}$ \\
\hline$(279-267)$ & $\begin{array}{l}\left(2 p_{3 / 2} 8 d_{5 / 2}\right)_{J=3}^{o}- \\
\left(2 p_{3 / 2} 8 p_{3 / 2}\right)_{J=2}^{e}\end{array}$ & E1 & 456.36 & $\begin{array}{l}g(\nu) \\
n_{e}\end{array}$ & & & & $\begin{array}{l}34.4 \\
5.3(21)\end{array}$ & $\begin{array}{l}90.5 \\
5.3(21)\end{array}$ \\
\hline$(276-265)$ & $\begin{array}{l}\left(2 p_{3 / 2} 8 d_{5 / 2}\right)_{J=4}^{o}- \\
\left(2 p_{3 / 2} 8 p_{3 / 2}\right)_{J=3}^{e}\end{array}$ & E1 & 459.38 & $\begin{array}{l}g(\nu) \\
n_{e}\end{array}$ & & & $\begin{array}{l}1.76 \\
5.2(21)\end{array}$ & $\begin{array}{l}69.6 \\
5.2(21)\end{array}$ & $\begin{array}{l}1.13 \mathrm{e}+02 \\
5.2(21)\end{array}$ \\
\hline$(267-257)$ & $\begin{array}{l}\left(2 p_{3 / 2} 8 p_{3 / 2}\right)_{J=2}^{e}- \\
\left(2 p_{3 / 2} 8 s_{1 / 2}\right)_{J=1}^{O}\end{array}$ & E1 & 461.74 & $\begin{array}{c}g(\nu) \\
n_{e}\end{array}$ & & $\begin{array}{l}1.31 \\
5.0(21)\end{array}$ & $\begin{array}{l}1.02 \mathrm{e}+02 \\
5.2(21)\end{array}$ & $\begin{array}{l}1.39 \mathrm{e}+02 \\
5.2(21)\end{array}$ & $\begin{array}{l}1.62 \mathrm{e}+02 \\
5.2(21)\end{array}$ \\
\hline$(266-257)$ & $\begin{array}{l}\left(2 p_{3 / 2} 8 p_{3 / 2}\right)_{J=1}^{e}- \\
\left(2 p_{3 / 2} 8 s_{1 / 2}\right)_{J=1}^{O}\end{array}$ & E1 & 478.23 & $\begin{array}{c}g(\nu) \\
n_{e}\end{array}$ & & & $\mathrm{C}_{2}$ & $\begin{array}{l}9.1 \\
4.8(21)\end{array}$ & $\begin{array}{l}14.4 \\
4.8(21)\end{array}$ \\
\hline$(265-262)$ & $\begin{array}{l}\left(2 p_{3 / 2} 8 p_{3 / 2}\right)_{J=3}^{e}- \\
\left(2 p_{3 / 2} 8 s_{1 / 2}\right)_{J=2}^{o}\end{array}$ & E1 & 573.82 & $\begin{array}{c}g(\nu) \\
n_{e}\end{array}$ & & & $\begin{array}{l}10.2 \\
3.3(21)\end{array}$ & $\begin{array}{l}22.0 \\
3.3(21)\end{array}$ & $\begin{array}{l}26.7 \\
3.3(21)\end{array}$ \\
\hline
\end{tabular}

Table 3: All wavelengths that appears at neon like Arsenic $A s^{+23}$ at five electron plasma temperatures $T_{e}$. Data are ordered according to their wavelengths. The index column is the transition energy index and ranges from 0 to 456, the transition column is the energy designation transition, the type column is the polarity type of the emitted radiation, $\lambda$ is the corresponding wavelength in $n m$, the G-E column is the maximum gain $g(\nu)$ with the corresponding electron density $n_{e}$ written as $a(b) \equiv a \times 10^{b}$ and $T_{e}$ is the electron plasma temperature in $\mathrm{eV}$. 
Doppler broadening were calculated for the highest gain transitions at five electron temperatures. The shortest X-ray laser wavelengths were dominant by the magnetic quadrupole emission M2 and the electric dipole E1.

Our calculations show a good agreement with the observed data, moreover more transitions were predicted with their wavelengths and gain values.

\section{References}

[1] P. L. Hagelstein, "Physics of short-wavelength-laser design," 1981.

[2] D. L. Matthews and M. D. Rosen, "Soft x-ray lasers," Scientific American;(USA), vol. 259, no. 6, 1988.

[3] J. G. Kepros, E. M. Eyring, and F. W. Cagle, "Experimental evidence of an x-ray laser," Proceedings of the National Academy of Sciences, vol. 69 , no. 7 , pp. $1744-1745,1972$.

[4] D. L. Matthews, P. Hagelstein, M. Rosen, M. Eckart, N. Ceglio, A. Hazi, H. Medecki, B. MacGowan, J. Trebes, B. Whitten, et al., "Demonstration of a soft x-ray amplifier," Physical review letters, vol. 54, no. 2, p. 110, 1985.

[5] C. Chenais-Popovics, R. Corbett, C. Hooker, M. Key, G. Kiehn, C. Lewis, G. Pert, C. Regan, S. Rose, S. Sadaat, et al., "Laser amplification at $18.2 \mathrm{~nm}$ in recombining plasma from a laser-irradiated carbon fiber," Physical review letters, vol. 59, no. 19, p. 2161, 1987.

[6] P. Jaeglé, G. Jamelot, A. Carillon, A. Klisnick, A. Sureau, and H. Guennou, "Soft-x-ray amplification by lithiumlike ions in recombining hot plasmas," JOSA B, vol. 4, no. 4, pp. 563-574, 1987.

[7] J. a. Dunn, A. Osterheld, R. Shepherd, W. White, V. Shlyaptsev, and R. Stewart, "Demonstration of x-ray amplification in transient gain nickel-like palladium scheme," Physical review letters, vol. 80, no. 13, p. 2825, 1998.

[8] J. Rocca, V. Shlyaptsev, F. Tomasel, O. Cortazar, D. Hartshorn, and J. Chilla, "Demonstration of a discharge pumped table-top soft-x-ray laser," Physical Review Letters, vol. 73, no. 16, p. 2192, 1994.

[9] P. V. Nickles, V. Shlyaptsev, M. Kalachnikov, M. Schnürer, I. Will, and W. Sandner, "Short pulse x-ray laser at $32.6 \mathrm{~nm}$ based on transient gain 
in ne-like titanium," Physical review letters, vol. 78, no. 14, p. 2748, 1997.

[10] M. Siegrist, F. Jia, and J. Balmer, "Self-photopumped x-ray lasers from elements in the Ne-like and Ni-like ionization state," in X-Ray Lasers 2014, pp. 89-93, Springer, 2016.

[11] J. Nilsen, "Comparing the Gain of the Ne K- $\alpha$ Inner-Shell X-Ray Laser Using the XFEL to Drive the Kinetics with Photo-Ionization Versus Photo-Excitation," in X-Ray Lasers 2014, pp. 209-215, Springer, 2016.

[12] N. Rohringer, D. Ryan, R. A. London, M. Purvis, F. Albert, J. Dunn, J. D. Bozek, C. Bostedt, A. Graf, R. Hill, et al., "Atomic inner-shell x-ray laser at 1.46 nanometres pumped by an x-ray free-electron laser," Nature, vol. 481, no. 7382, pp. 488-491, 2012.

[13] J. Balmer, F. Staub, and F. Jia, "Soft-x-ray lasing down to $6.85 \mathrm{~nm}$ in ni-like samarium," in X-Ray Lasers 2012, pp. 29-34, Springer, 2014.

[14] E. McLean, T. Lee, J. Stamper, C. Manka, and H. Griem, "Measurements on collisionally excited soft-x-ray lasers," JOSA B, vol. 9, no. 3, pp. 350-359, 1992.

[15] M. F. Gu, "The flexible atomic code," Canadian Journal of Physics, vol. 86, no. 5, pp. 675-689, 2008.

[16] S. Hamasha, "Energy levels, wavelengths, and transition rates of multipole transitions $(E 1, E 2, M 1, M 2)$ in $A u^{+67}$ and $A u^{+66}$ ions," Atomic Data and Nuclear Data Tables, vol. 99, no. 6, pp. 595-632, 2013.

[17] D. J. Griffiths, Introduction to quantum mechanics. Benjamin Cummings, 2 ed., 2004.

[18] B. L. Moiseiwitsch and S. J. Smith, "Electron impact excitation of atoms," Reviews of Modern Physics, vol. 40, no. 2, p. 238, 1968.

[19] F. P. Aggarwal, Kanti M.; Keenan, "Energy levels, radiative rates, and electron impact excitation rates for transitions in li-like ions with," Atomic Data and Nuclear Data Tables, vol. 98, 112012.

[20] M. Rosen, P. Hagelstein, D. Matthews, E. Campbell, A. Hazi, B. Whitten, B. MacGowan, R. Turner, R. Lee, G. Charatis, et al., "Explodingfoil technique for achieving a soft x-ray laser," Physical review letters, vol. 54, no. 2, p. 106, 1985. 
[21] B. MacGowan, L. Da Silva, D. Fields, C. Keane, J. Koch, R. London, D. Matthews, S. Maxon, S. Mrowka, A. Osterheld, et al., "Short wavelength $\mathrm{x}$-ray laser research at the lawrence livermore national laboratory," Physics of Fluids B: Plasma Physics (1989-1993), vol. 4, no. 7, pp. 2326-2337, 1992.

[22] W. H. Goldstein, B. L. Whitten, A. U. Hazi, and M. H. Chen, "Mechanisms for creating population inversions in ne-like ions," Physical Review A, vol. 36, no. 8, p. 3607, 1987.

[23] A. Calisti, S. Ferri, C. Mossé, B. Talin, A. Klisnick, L. Meng, D. Benredjem, and O. Guilbaud, "Study of particle correlation effects on line profiles of ni-like collisional xuv laser amplifier," in X-Ray Lasers 2012, pp. 49-53, Springer, 2014.

[24] R. C. Elton, X-ray Lasers. Elsevier, 2012.

[25] L. Meng, A. Klisnick, M. Kozlova, K. Bohacek, M. Krus, J. Prokupek, L. Urbanski, M. Marconi, M. Berrill, J. Rocca, et al., "Temporal coherence and spectral linewidth of neon-like xuv lasers pumped in the quasisteady state regime," in X-Ray Lasers 2012, pp. 175-180, Springer, 2014.

[26] L. Urbanski, M. Marconi, L. Meng, M. Berrill, O. Guilbaud, A. Klisnick, and J. Rocca, "Spectral linewidth measurement of a ne-like ar capillary discharge soft x-ray laser," in X-Ray Lasers 2012, pp. 257-261, Springer, 2014 .

[27] A. S. E.-S. T. Yahia M.E., Azzouz I.M., "Laser gain by electron collisional pumping of ar vii- v xii," Optics \& Laser Technology, p. 10081017, 2008.

[28] A. Kramida, Yu. Ralchenko, J. Reader, and and NIST ASD Team. NIST Atomic Spectra Database (ver. 5.3), [Online]. Available: http://physics.nist.gov/asd [2016, February 4]. National Institute of Standards and Technology, Gaithersburg, MD., 2015. 